\title{
Nitrate Sorption in an Agricultural Soil Profile
}

\author{
Wissem Hamdi, ${ }^{1}$ Faten Gamaoun, ${ }^{2}$ David E. Pelster, ${ }^{3}$ and Mongi Seffen ${ }^{4}$ \\ ${ }^{1}$ High Institute of Agronomy, Sousse University, Chott Meriem, 4042 Sousse, Tunisia \\ ${ }^{2}$ Applied Chemistry and Environment Research Unit, EPAM, 4000 Sousse, Tunisia \\ ${ }^{3}$ International Livestock Research Institute, P.O. Box 30709, Nairobi, Kenya \\ ${ }^{4}$ Laboratory of Energy and Materials (LABEM), High School of Sciences and Technology, Sousse University, \\ 4011 Hammam Sousse, Tunisia \\ Correspondence should be addressed to Wissem Hamdi; wissemhemdi@yahoo.fr
}

Received 6 March 2013; Revised 9 June 2013; Accepted 25 June 2013

Academic Editor: Marco Trevisan

Copyright (C) 2013 Wissem Hamdi et al. This is an open access article distributed under the Creative Commons Attribution License, which permits unrestricted use, distribution, and reproduction in any medium, provided the original work is properly cited.

Increasing concentrations of $\mathrm{NO}_{3}{ }^{-}$in surface water and groundwater can cause ecological and public health effects and has come under increased scrutiny by both environmental scientists and regulatory agencies. For many regions though, including the Sahel of Tunisia, little is known about the $\mathrm{NO}_{3}{ }^{-}$sorption capacity of soils. In this project we measured $\mathrm{NO}_{3}{ }^{-}$sorption by a profile of an isohumic soil from Chott Meriem, Tunisia. Soil samples were collected from four soil depths $(0-25,25-60,60-90$, and 90-120 cm) on 1 June 2011, and their sorption capacity was determined using batch experiments under laboratory conditions. The effects of contact time, the initial concentration, and the soil-solution ratio on $\mathrm{NO}_{3}{ }^{-}$sorption were investigated. In general, the results suggested that $\mathrm{NO}_{3}{ }^{-}$was weakly retained by the Chott Meriem soil profile. The quantity of $\mathrm{NO}_{3}{ }^{-}$sorption increased with depth, contact time, initial concentration, and soil-solution ratios. To evaluate the sorption capacities of the soil samples at concentrations ranging between 25 and $150 \mathrm{mg} \mathrm{L}^{-1}$ experimental data were fitted to both Freundlich and Langmuir isotherm sorption models. The results indicated that Freundlich model was better for describing $\mathrm{NO}_{3}{ }^{-}$sorption in this soil profile.

\section{Introduction}

Nitrogen $(\mathrm{N})$ is a critical nutrient needed by all plants for growth [1]. Input of inorganic $\mathrm{N}$ as a fertilizer is considered essential in modern agriculture in order to satisfy the dietary needs of a growing world population. Nitrate $\left(\mathrm{NO}_{3}{ }^{-}\right)$is the one of the principal $\mathrm{N}$ forms taken up by plants. As such, inorganic $\mathrm{N}$ is widely used in agriculture and numerous studies have suggested that leaching of $\mathrm{NO}_{3}{ }^{-}$following high input rates of chemical fertilizer and due to mineralization of organic $\mathrm{N}$ already present in the soils can cause degradation of surface and groundwater quality. Excess $\mathrm{NO}_{3}{ }^{-}$ contaminated water supplies have been linked to outbreaks of infectious disease [2]. Also, $\mathrm{NO}_{3}{ }^{-}$can be converted to nitrite in the digestive tracts of infants and ruminant animals, which then combines with blood hemoglobin, reducing its ability to carry oxygen, occasionally leading to death. The ability of soil to adsorb anions can reduce $\mathrm{NO}_{3}{ }^{-}$leaching to the deeper horizons and maximize the $\mathrm{NO}_{3}{ }^{-}$available for plant nutrition and can thus play a fundamental role in enhancing soil nutrition in regions, such as Mediterranean areas, where $\mathrm{NO}_{3}{ }^{-}$availability is often a limiting factor [3]. Previous studies have reported the sorption of $\mathrm{NO}_{3}{ }^{-}$by soils $[4,5]$. However, $\mathrm{NO}_{3}{ }^{-}$mobility in soils is mainly controlled by a number of soil properties including iron and aluminum oxide concentrations [6], organic matter content [7], $\mathrm{pH}$ of soil solutions [8], and soil texture and clay mineralogy [9]. Other studies suggested that sorption of $\mathrm{NO}_{3}{ }^{-}$was influenced by the competition with other anions as $\mathrm{Cl}^{-}[10]$. Qafoku et al. [11] reported that $\mathrm{NO}_{3}{ }^{-}$sorption was directly related to $\mathrm{NO}_{3}{ }^{-}$ concentration in the soil solution.

The $\mathrm{NO}_{3}{ }^{-}$sorption process has been studied in many different soil orders in tropical latitudes [12], including Oxisols [13] as well as in ultisols of the southeastern and midAtlantic United States [14] and in forest soils of the American northwest [15]. However, none of these investigated $\mathrm{NO}_{3}{ }^{-}$ dynamics for the soils of Tunisia, in particular the soils of the Sousse region, which is considered to be one of the most important crop production areas in Tunisia. The aim of this 
TABLE 1: Physiochemical properties of iso-humic soil from Chott Mariam.

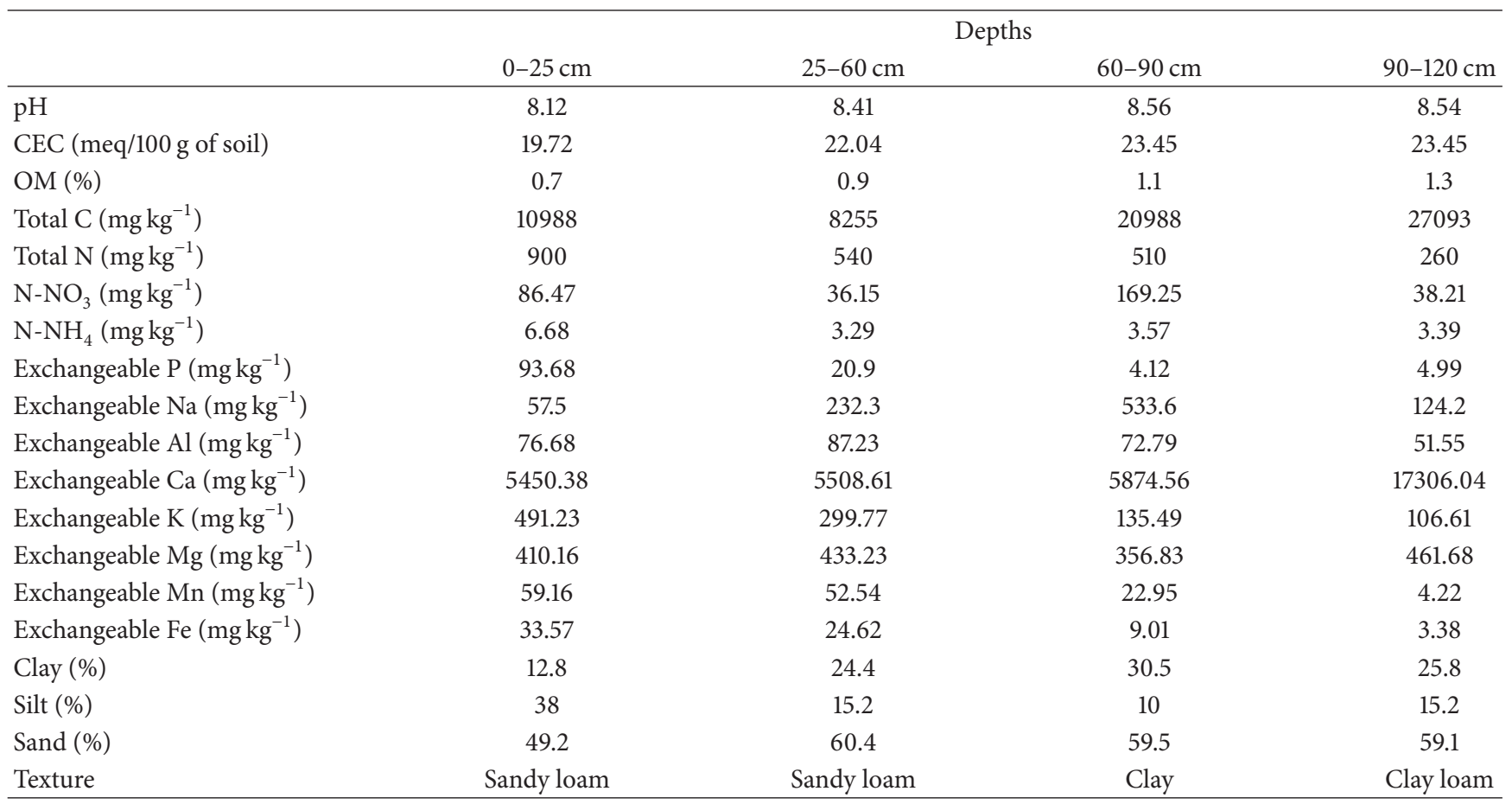

study was to investigate the $\mathrm{NO}_{3}{ }^{-}$sorption capacity of these soils by soil depth.

\section{Materials and Methods}

2.1. Site Description. Soil samples were collected from a citrus orchard at the High Agronomic Institute of Chott Meriem Sousse, $\left(35^{\circ} 54^{\prime} \mathrm{N} 10^{\circ} 36^{\prime} \mathrm{E}\right)$ on 1 June 2011 . The climate is Mediterranean and is characterized by hot dry summers and moderate wet winters, an average annual precipitation of $230 \mathrm{~mm}$ and a mean annual temperature of $18.5^{\circ} \mathrm{C}$. Ammonium nitrate fertilizer is applied annually at a rate of $200 \mathrm{~kg} \mathrm{~N} \mathrm{ha}^{-1}$. The soils are medium-textured brown iso-humic [16], with an average infiltration rate of $45 \mathrm{~mm} \mathrm{~h}^{-1}$.

2.2. Chemical Analysis. Four soil pits were sampled to a depth of $120 \mathrm{~cm}$ and separated into four depths: 0-25, 25-60, 60-90, and $90-120 \mathrm{~cm}$. Samples were air-dried and ground to pass a $2 \mathrm{~mm}$ sieve. Soil $\mathrm{pH}$ was determined in $1: 2$ soil : water suspension [17]; organic matter (OM) determined by the wet oxidation method (Walkley and Black); particle-size distribution by the pipette method [18]; cation exchange capacity (CEC) by the $\mathrm{BaCl}_{2}$ extraction method [19]. Mehlich-III [20], P, Ca, $\mathrm{Mg}, \mathrm{Fe}, \mathrm{Al}, \mathrm{Cd}, \mathrm{Cu}$, and $\mathrm{Mn}$ were determined by equilibrating $2.5 \mathrm{~g}$ of air-dried soil sample with $25 \mathrm{~mL}$ of Mehlich-III extracting solution for $5 \mathrm{~min}$ and filtering through Whatman no. 40 filter paper. The different concentrations in the extracts were measured using an inductively coupled plasma optical emission spectrometer (Perkins Elmer, Model 4300DV). Soil $\mathrm{N}-\mathrm{NO}_{3}{ }^{-}$and $\mathrm{N}-\mathrm{NH}_{4}{ }^{+}$concentrations were analysed using the steam distillation method [21].
2.3. Batch Study. The $\mathrm{NO}_{3}{ }^{-}$sorption on the iso-humic soil of Chott Meriem was studied as a function of the soil to soil-solution $\mathrm{NO}_{3}{ }^{-}$ratio. Nitrate sorption in each horizon was determined via batch equilibration techniques adapted from [14]. The following soil: solution ratios $(1 \%, 12.5 \%, 25 \%$, and 50\%) have been proposed in the literature [22] and were used in this study. The concentration of the solution was $100 \mathrm{mg} \mathrm{NO}_{3}{ }^{-} \mathrm{L}^{-1}$. The temperature was $20^{\circ} \mathrm{C}$. Briefly $5 \mathrm{~g}$ of air-dried soil from each soil subsample was equilibrated with $100 \mathrm{~mL}$ of $\mathrm{NO}_{3}{ }^{-}$solution. Two drops of toluene were added to each mixture to prevent any biological $\mathrm{NO}_{3}{ }^{-}$transformations. Equilibration was estimated to have occurred after the mixture was shaken on a reciprocal shaker at $20^{\circ} \mathrm{C}$ for $1 \mathrm{~h}$ at a rate of 100 oscillations/min. After equilibration the mixtures were centrifuged at $5000 \mathrm{rpm}$ for $10 \mathrm{~min}$ and the $\mathrm{NO}_{3}{ }^{-}$concentration of the supernatant was determined immediately using a spectrophotometer at $220 \mathrm{~nm}$.

The amount of adsorption at equilibrium $Q_{e}\left(\mathrm{mg} \mathrm{g}^{-1}\right)$ was calculated by

$$
Q_{e}=\left(\frac{C_{i}-C_{e}}{M}\right) \times V
$$

where $C_{i}$ and $C_{e}\left(\mathrm{mg} \mathrm{L}^{-1}\right)$ are the liquid-phase concentrations of $\mathrm{NO}_{3}{ }^{-}$at initial conditions and at equilibrium, respectively. $V$ is the volume of the solution (L). $M$ is the mass of dry adsorbent used (g).

\section{Results and Discussion}

3.1. Soil Properties. The main soil properties thought to influence $\mathrm{NO}_{3}{ }^{-}$sorption and movement are provided in Table 1. 
The $\mathrm{pH}$ for these soil horizons were all above 8 , while soil texture varied between fine sandy loam and sandy clay loam in the two first horizons $(0-25 \mathrm{~cm})$ and $(25-60 \mathrm{~cm})$ and clay and sandy clay loam, for the two next deeper horizons $(60-90 \mathrm{~cm}$ and $90-120 \mathrm{~cm})$, respectively. The variation in texture reflected the differences in parent materials [23]. Clay content, which tended to increase with depth, can affect soil fertility and water and nutrient holding capacities as well as plant root movement [24]. The organic matter content for the different soils horizons showed a similar pattern to the clay, where the concentrations tended to increase in the deeper horizons (Table 1). It has been reported that $\mathrm{NO}_{3}{ }^{-}$ mobility is often related to the organic matter content and could be due to the higher cation exchange capacity [25]. The amount of exchangeable cations differed markedly; $\mathrm{Ca}^{2+}$ concentrations were high in the different horizons and tended to increase at depth. The inverse can be seen for other exchangeable cations such $\mathrm{K}^{+}$and $\mathrm{Fe}^{2+}$ where concentrations were moderate and decreased with increasing depth. For the other ions there were no distinct patterns in terms of the amount and distribution within the different horizons of the soil profile.

3.2. Effect of Contact Time on $\mathrm{NO}_{3}{ }^{-}$Sorption. As shown in Figure 1, the $\mathrm{NO}_{3}{ }^{-}$adsorption rate was rapid for the first $60 \mathrm{~min}$ and decreased over time. Equilibrium sorption was established after approximately $120 \mathrm{~min}$ for $\mathrm{NO}_{3}{ }^{-}$ions at an initial concentration of $100 \mathrm{mg} \mathrm{L}^{-1}$. From the results it can be seen that the contact time required for maximum sorption of $\mathrm{NO}_{3}{ }^{-}$by different soil profile was dependent on the initial $\mathrm{NO}_{3}{ }^{-}$concentration and on certain soil components, especially the $\mathrm{OM}$ and clay content. This behavior suggests that at the initial stage, sorption takes place rapidly on the external surface of the adsorbent followed by a slower internal diffusion process, which may be the rate-determining step. This trend in $\mathrm{NO}_{3}{ }^{-}$sorption suggests that the binding may be through interactions with functional groups located on the surface of the soil. According to these results, the contact time was fixed at $120 \mathrm{~min}$ for the batch experiments to make sure that equilibrium was attained. The results demonstrated that at a fixed adsorbent dosage, the $\mathrm{NO}_{3}{ }^{-}$sorption was higher in deeper horizons than in superficial horizons. The two deepest horizons contained more organic matter, which counterbalances the effect of positive charges of the oxides on $\mathrm{NO}_{3}{ }^{-}$ sorption. Indeed, organic groups displace water ligands at the positively charged sites on surfaces oxides [26]. As shown in Table 1 the amount of clay increased with depth along with increasing $\mathrm{CEC}$, which enhances the $\mathrm{NO}_{3}{ }^{-}$sorption capacity.

3.3. Effect of Soil-Solution Ratios on $\mathrm{NO}_{3}{ }^{-}$Sorption. The sorption of $\mathrm{NO}_{3}{ }^{-}$on iso-humic soil of Chott Meriem was studied as a function of the soil to soil-solution $\mathrm{NO}_{3}{ }^{-}$ratio. The following soil : solution ratios $(1 \%, 12.5 \%, 25 \%$, and $50 \%)$ have been proposed in the literature [22] and used in this study. The experiment was conducted in batch. As shown in Figure 2 there was not a lot of variation between the different depths in the $\mathrm{NO}_{3}{ }^{-}$adsorption capacity at a low soil : solution ratio (1\%). However, the $\mathrm{NO}_{3}{ }^{-}$sorption capacity increased with an increase in the soil: solution ratio. When the ratio increased

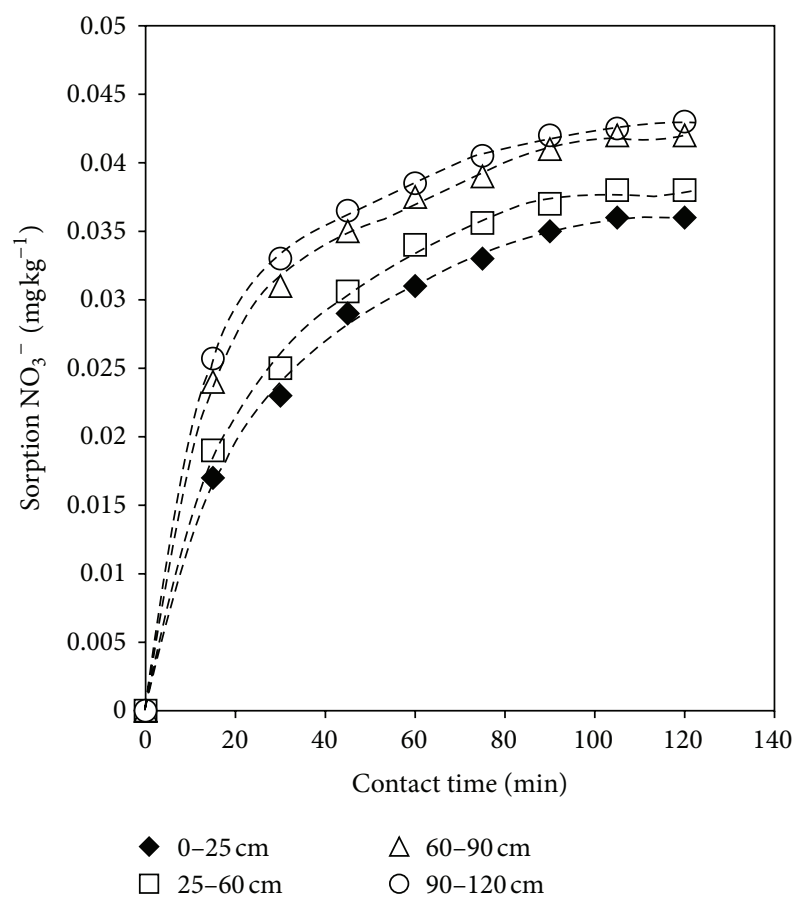

Figure 1: Effect of contact time on $\mathrm{NO}_{3}{ }^{-}$sorption for 4 soil depths from a batch experiment using an iso-humic soil from Chott Meriam, Tunisia. (Initial conditions for the batch experiment were $100 \mathrm{mg} \mathrm{NO}_{3}{ }^{-} \mathrm{L}^{-1}, 22^{\circ} \mathrm{C}$, and $5 \mathrm{~g}$ air-dried soil).

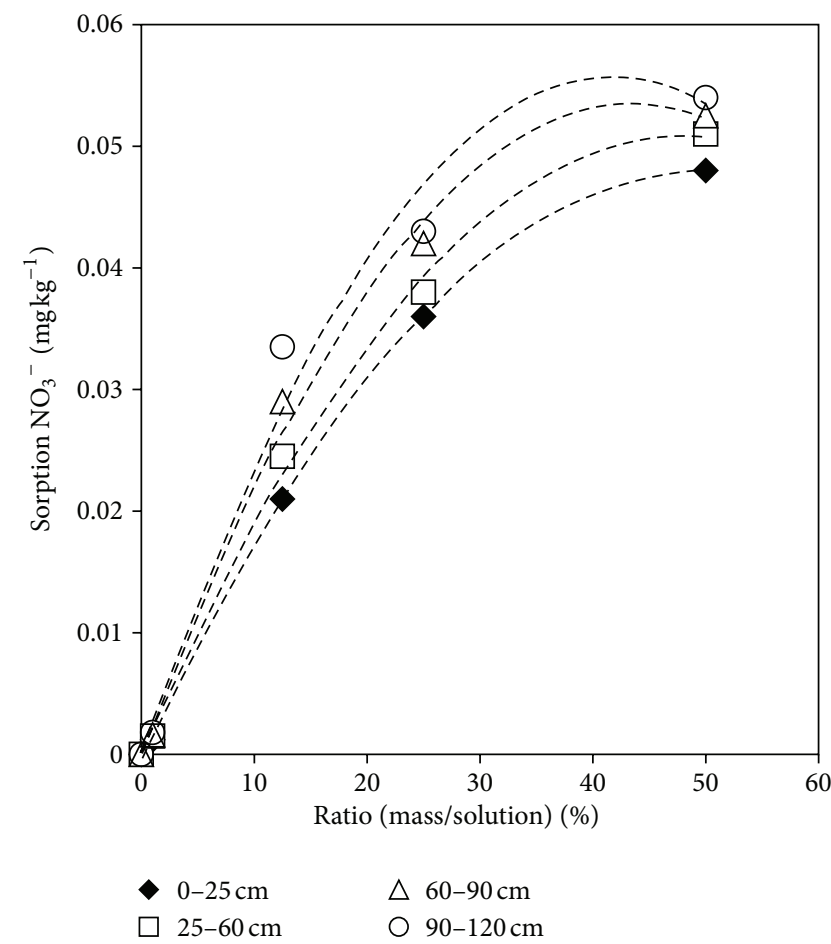

FIgURE 2: Effect of soil-solution ratios on $\mathrm{NO}_{3}{ }^{-}$sorption for 4 soil depths from a batch experiment using an iso-humic soil from Chott Meriam, Tunisia (soil/solution ratios: $1 \%, 12.5 \%, 25 \%$, and $50 \%$, $\left.22^{\circ} \mathrm{C}, 24 \mathrm{~h}\right)$. 


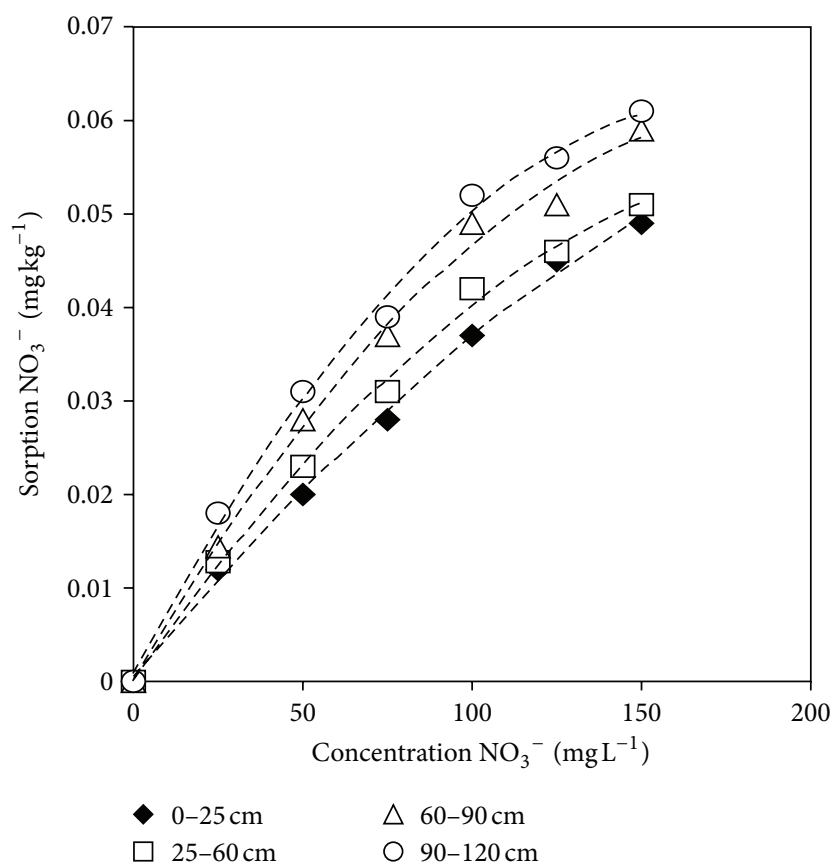

Figure 3: Effect of initial $\mathrm{NO}_{3}{ }^{-}$concentration on $\mathrm{NO}_{3}{ }^{-}$sorption for 4 soil depths from a batch experiment using an iso-humic soil from Chott Meriam, Tunisia $\left(25,50,75,100,125\right.$, and $150 \mathrm{mg} \mathrm{L}^{-1}, 22^{\circ} \mathrm{C}, 24 \mathrm{~h}$, and soil mass $\left.=5 \mathrm{~g}\right)$.

TABLE 2: Langmuir and Freundlich parameters for sorption of $\mathrm{NO}_{3}{ }^{-}$on four depths of iso-humic soil from Chott Mariam, Tunisia.

\begin{tabular}{lccccc}
\hline & & & \multicolumn{2}{c}{ Depths } \\
& & $0-25 \mathrm{~cm}$ & $25-60 \mathrm{~cm}$ & $60-90 \mathrm{~cm}$ & $90-120 \mathrm{~cm}$ \\
\hline \multirow{3}{*}{ Langmuir parameters } & $Q(\mathrm{mg} / \mathrm{g})$ & 0.153 & 0.134 & 0.144 & 0.0046 \\
& $K_{L}(\mathrm{~L} / \mathrm{mg})$ & 0.0031 & 0.0041 & 0.93 & 0.0068 \\
\hline \multirow{3}{*}{ Freundlich parameters } & $R^{2}$ & 0.89 & 0.95 & 0.0012 & 0.002 \\
& $K_{F}$ & 0.00086 & 0.001 & 1.28 & 0.98 \\
\hline
\end{tabular}

from $1 \%$ to $50 \%$, the $\mathrm{NO}_{3}{ }^{-}$sorption capacities increased from 0.0012 to $0.048,0.0015$ to $0.051,0.0016$ to 0.0525 , and 0.0018 to 0.054 for the $0-25,25-60,60-90$, and $90-120 \mathrm{~cm}$ depths, respectively. These observations infer that increasing soil : solution ratios play a major role in the increasing $\mathrm{NO}_{3}{ }^{-}$ sorption capacity by the soils, similar to results obtained by Qafoku et al. [11]. It can be noted that the ratio increases as the mass of soil increases. It has been suggested that increased soil mass causes increased variable charges in the solution and consequently increased sorption of $\mathrm{NO}_{3}{ }^{-}$. Furthermore, it was reported that $\mathrm{NO}_{3}{ }^{-}$mobility was often related to the active components of organic matter and the clay-sized fractions [27], likely due to the resulting increase in CEC [25].

3.4. Effect of Initial $\mathrm{NO}_{3}{ }^{-}$Concentration on $\mathrm{NO}_{3}{ }^{-}$Sorption. Seeing that the initial $\mathrm{NO}_{3}{ }^{-}$concentration in solution provides an important driving force to overcome mass transfer limitations of $\mathrm{NO}_{3}{ }^{-}$between aqueous and solid phases, a higher initial $\mathrm{NO}_{3}^{-}$- concentration will increase the sorption process. The effect of initial $\mathrm{NO}_{3}{ }^{-}$concentration on $\mathrm{NO}_{3}{ }^{-}$sorption for all soil depths was investigated in the following concentrations $(25,50,75,100,125$, and $150 \mathrm{mg}$ $\mathrm{NO}_{3}{ }^{-} \mathrm{L}^{-1}$ ). Figure 3 shows the change of the equilibrium sorption capacity of soil samples with different initial $\mathrm{NO}_{3}{ }^{-}$ concentrations. It was observed that the amount of sorbed $\mathrm{NO}_{3}{ }^{-}$at equilibrium increased with increasing initial $\mathrm{NO}_{3}{ }^{-}$ concentration for all soil horizons, although rates differed according to the soil layer.

Many previous works reported that at low concentration, more $\mathrm{NO}_{3}{ }^{-}$is sorbed by the soil than is left in solution. There is some controversy concerning the mechanism of $\mathrm{NO}_{3}{ }^{-}$ adsorption at low concentration in soil. Toner et al. [28] proposed a totally reversible adsorption, which is a simple electrostatic retention (i.e., the adsorption is the result of van der Waals type interactions). On the contrary, Qafoku et al. [11] explained the adsorption as an overlapping or interpenetration of double layers around positively charged Al-polymers and negatively charged silicate minerals.

Below concentrations of $100 \mathrm{mg} \mathrm{NO}_{3}{ }^{-} \mathrm{L}^{-1}, \mathrm{NO}_{3}{ }^{-}$sorption was low in the top horizon $(0-25 \mathrm{~cm})$, higher in the $25-$ $60 \mathrm{~cm}$ horizon, and peaked within the $60-90 \mathrm{~cm}$ and $90-$ $120 \mathrm{~cm}$ depths. Above concentrations of $125 \mathrm{NO}_{3}{ }^{-} \mathrm{mg} \mathrm{L}^{-1}$, 


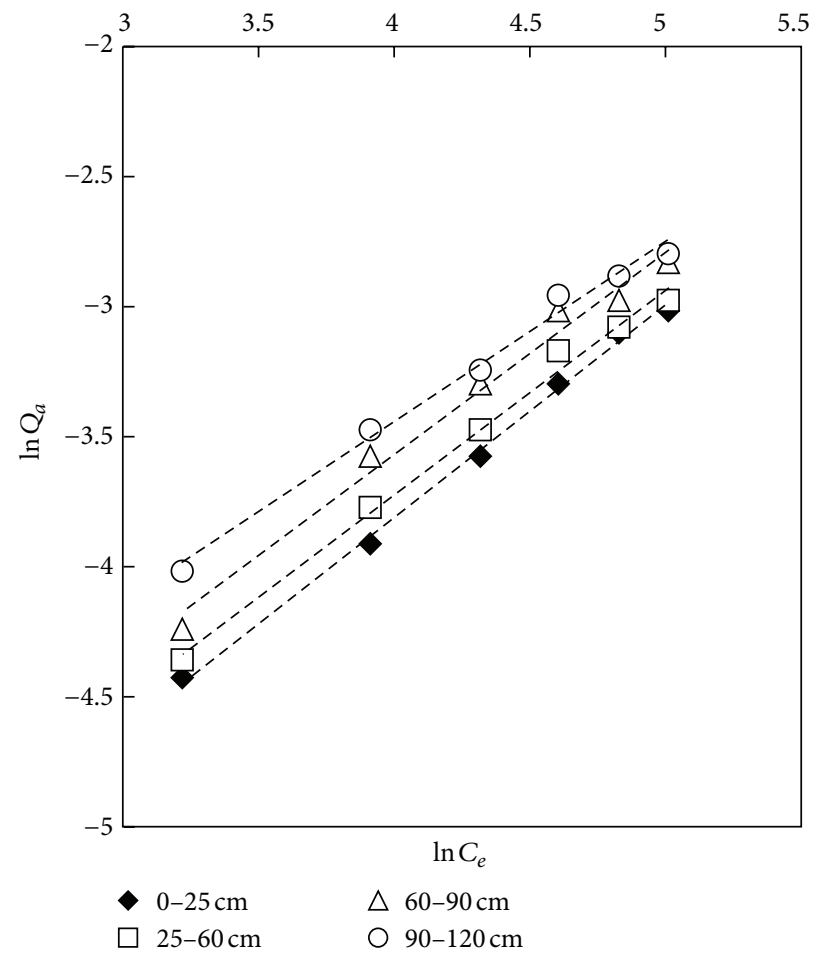

FIgURE 4: Langmuir isotherms for $\mathrm{NO}_{3}{ }^{-}$sorption by soil profile at $\left(25,50,75,100,125\right.$, and $150 \mathrm{mg} \mathrm{NO}_{3}{ }^{-} \mathrm{L}^{-1}, 22^{\circ} \mathrm{C}, 24 \mathrm{~h}$, and soil mass $\left.=5 \mathrm{~g}\right)$.

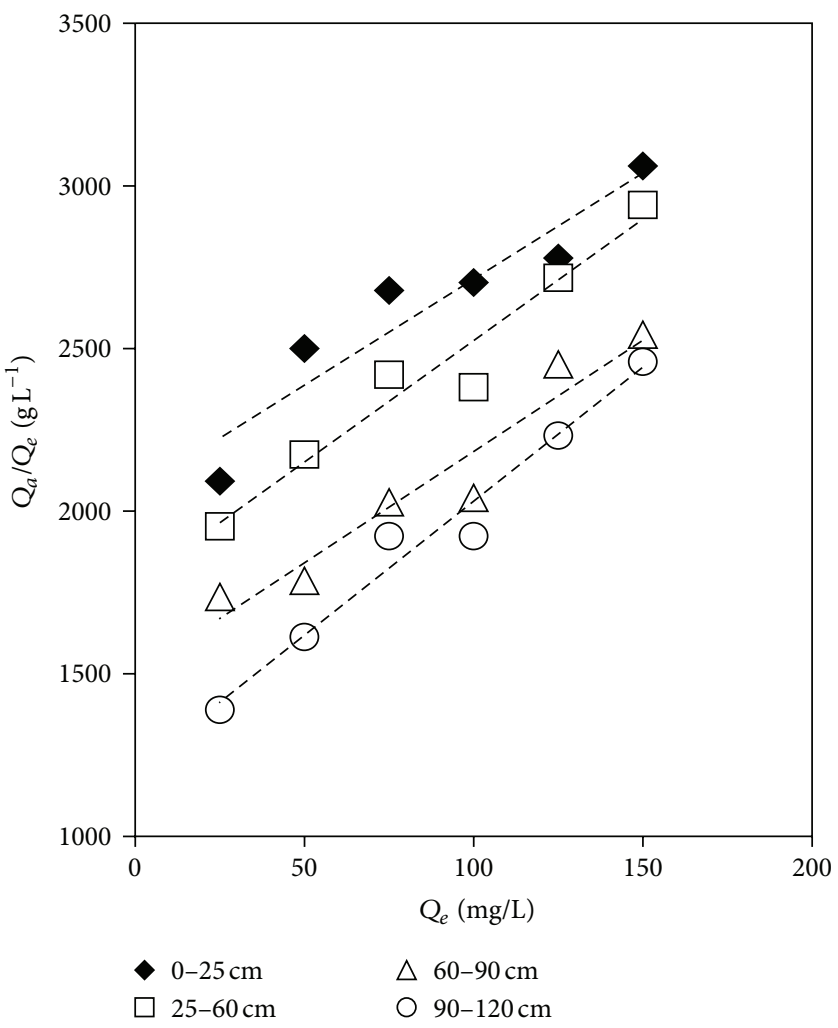

Figure 5: Freundlich isotherms for $\mathrm{NO}_{3}{ }^{-}$sorption by soil profile at $\left(25,50,75,100,125\right.$, and $150 \mathrm{mg} \mathrm{NO}_{3}{ }^{-} \mathrm{L}^{-1}, 22^{\circ} \mathrm{C}, 24 \mathrm{~h}$, and soil mass $=$ $5 \mathrm{~g})$. 
the slope of the curves decreased. This decline in $\mathrm{NO}_{3}{ }^{-}$ sorption with increased initial concentrations in all soil depths is likely due to the weakening of attractive forces between $\mathrm{NO}_{3}{ }^{-}$and the soil matrix as well as desorption of other anions (e.g., P) as suggested by Strahm and Harrison [15].

3.5. Adsorption Equilibrium and Isotherms. To facilitate the estimation of the $\mathrm{NO}_{3}{ }^{-}$sorption capacities of the soils at the following concentrations $(25,50,75,100,125$, and $150 \mathrm{mg} \mathrm{NO}_{3}{ }^{-} \mathrm{L}^{-1}$ ), the experimental data were fitted to the Freundlich and Langmuir equilibrium adsorption isotherm models. The Langmuir equation is as follows: $C_{e} / Q_{e}=$ $1 / Q_{m} b+C_{e} / Q_{m}$, where $C_{e}$ is the equilibrium concentration of $\mathrm{NO}_{3}{ }^{-}$in the solution $(\mathrm{mg} / \mathrm{L}), Q_{e}$ the amount of $\mathrm{NO}_{3}{ }^{-}$ sorbed per unit weight of soil $\left(\mathrm{mg} \mathrm{kg}^{-1}\right)$, and $Q_{m}$ and $b$ are the Langmiur constants signifying the sorption capacity of the adsorbent and energy of the sorption process, respectively. The sorption data was plotted (Figure 4 ), and $Q_{m}$ and $K_{L}$ (listed in Table 2) were calculated from the intercept and the slope of the plots.

The Langmuir equation characterized the $\mathrm{NO}_{3}{ }^{-}$sorption data fairly well, with $R^{2}$ values between 0.89 and 0.97 for the different soil horizons (Table 2). The adjusted $R^{2}$ values suggest that the Langmuir isotherm provides a good model of the sorption system only for the $25-60 \mathrm{~cm}$ and $90-120 \mathrm{~cm}$ horizons. In this work, it appears that the $Q_{m}$ was greatest in the surface horizon and tended to decrease with depth. However, $K_{L}$ increased with depth, which suggests that not all inorganic sites may be available for $\mathrm{NO}_{3}{ }^{-}$binding [15].

The Freundlich equation is as follows: $\ln \left(q_{e}\right)=\ln \left(K_{F}\right)+$ $(1 / n) \ln \left(C_{e}\right)$, where $q_{e}$ is the amount of $\mathrm{NO}_{3}{ }^{-}$per gram of soil at the equilibrium, $\mathrm{C}$ is the $\mathrm{NO}_{3}{ }^{-}$concentration in solution at the equilibrium, and $K$ and $n$ are the empirical constants indicating the adsorption capacity and adsorption intensity, respectively. Figure 5 shows the plot of $\ln \left(q_{e}\right)$ versus $\ln \left(C_{e}\right)$, enabling the constants $K$ and $n$ to be determined from the intercept and slope, respectively (Table 2 ). The $R^{2}$ values for the Freundlich isotherm model were greater than those from the Langmuir model (Table 2). The values of $n$ for all soil samples were found to be nearly similar at all depths, indicating reasonable sorption of $\mathrm{NO}_{3}{ }^{-}$onto soil samples at the concentration studied, as is evident from Table 2. Additionally it can be also shown that the values of $\left(K_{F}\right)$, which is a measure of the degree of sorption, decrease at greater depths, consistent with previous studies [15].

\section{Conclusion}

In this study, the sorption of $\mathrm{NO}_{3}{ }^{-}$from aqueous solutions onto alkaline soils of the Chott Meriem region was examined. The results indicated that the soil $\mathrm{NO}_{3}{ }^{-}$sorption capacity of different horizons was affected by the ratio of the soil mass and solution volume, the initial $\mathrm{NO}_{3}{ }^{-}$concentration, and the contact time. The amount of $\mathrm{NO}_{3}{ }^{-}$sorbed on soils increased with depth. However, a considerable amount of $\mathrm{NO}_{3}{ }^{-}$in the soil was not sorbed by the soil and, thus, it is expected that the majority of $\mathrm{NO}_{3}{ }^{-}$in excess of biological immobilization rates will be transported through the soils into ground or surface waters. Also, although both Langmuir and Freundlich isotherm models were used to describe the sorption behavior of $\mathrm{NO}_{3}{ }^{-}$on soil samples, the Freundlich adsorption isotherm model better described the $\mathrm{NO}_{3}{ }^{-}$sorption in this soil profile.

\section{References}

[1] N. M. Crawford and A. D. M. Glass, "Molecular and physiological aspects of nitrate uptake in plants," Trends in Plant Science, vol. 3, no. 10, pp. 389-395, 1998.

[2] L. Fewtrell, "Drinking-water nitrate, methemoglobinemia, and global burden of disease: a discussion," Environmental Health Perspectives, vol. 112, no. 14, pp. 1371-1374, 2004.

[3] F. A. Rutigliano, S. Castaldi, R. D’Ascoli et al., "Soil activities related to nitrogen cycle under three plant cover types in Mediterranean environment," Applied Soil Ecology, vol. 43, no. 1, pp. 40-46, 2009.

[4] J. S. Reynolds-Vargas, D. D. Richter, and E. Bornemisza, "Environmental impacts of nitrification and nitrate adsorption in fertilized andisols in the Valle Central of Costa Rica," Soil Science, vol. 157, no. 5, pp. 289-299, 1994.

[5] M. Tani, T. Okuten, M. Koike, K. Kuramochi, and R. Kondo, "Nitrate adsorption in some andisols developed under different moisture conditions," Soil Science and Plant Nutrition, vol. 50, no. 3, pp. 439-446, 2004.

[6] M. T. F. Wong and K. Wittwer, "Positive charge discovered across Western Australian wheatbelt soils challenges key soil and nitrogen management assumptions," Australian Journal of Soil Research, vol. 47, no. 1, pp. 127-135, 2009.

[7] M. R. Panuccio, A. Muscolo, and S. Nardi, "Effect of humic substances on nitrogen uptake and assimilation in two species of pinus," Journal of Plant Nutrition, vol. 24, no. 4-5, pp. 693704, 2001.

[8] M. J. Donn and N. W. Menzies, "Simulated rainwater effects on anion exchange capacity and nitrate retention in Ferrosols," Australian Journal of Soil Research, vol. 43, no. 1, pp. 33-42, 2005.

[9] N. Martínez-Villegas, L. M. Flores-Vélez, and O. Domínguez, "Sorption of lead in soil as a function of $\mathrm{pH}$ : a study case in México," Chemosphere, vol. 57, no. 10, pp. 1537-1542, 2004.

[10] F. Feder and A. Findeling, "Retention and leaching of nitrate and chloride in an andic soil after pig manure amendment," European Journal of Soil Science, vol. 58, no. 2, pp. 393-404, 2007.

[11] N. P. Qafoku, M. E. Sumner, and D. E. Radcliffe, "Anion transport in columns of variable charge subsoils: nitrate and chloride," Journal of Environmental Quality, vol. 29, no. 2, pp. 484493, 2000.

[12] T. Kinjo and P. F. Pratt, "Nitrate adsorption: I. some acid soils of Mexico and South America," Soil Science Society of America Proceedings, vol. 35, pp. 722-725, 1971.

[13] J. F. Dynia, "Nitrate retention and leaching in variable charge soils of a watershed in Sao Paulo state, Brazil," Communications in Soil Science and Plant Analysis, vol. 31, no. 5-6, pp. 777-791, 2000.

[14] M. J. Eick, W. D. Brady, and C. K. Lynch, "Charge properties and nitrate adsorption of some acid Southeastern soils," Journal of Environmental Quality, vol. 28, no. 1, pp. 138-144, 1999. 
[15] B. D. Strahm and R. B. Harrison, "Nitrate sorption in a variablecharge forest soil of the Pacific Northwest," Soil Science, vol. 171, no. 4, pp. 313-321, 2006.

[16] FAO, "Soil map of world," FAO Word Soil Report 60, FAO, Rome, Italy, 1989.

[17] T. P. Hignett, "Fertilizer manual," Developments in Plant and Soil Science, vol. 315, pp. 163-186, 1985.

[18] G. W. Gee and J. W. Bauder, Particle Size Analysis, 1986.

[19] W. H. Hendershot, H. Lalande, and M. Duquette, "Ion exchange and exchangeable cations," in Soil Sampling and Methods of Analysis, R. C. Martin, Ed., pp. 183-205, Canadian Society of Soil Science, Lewis Publishers, Boca Raton, Fla, USA, 1993.

[20] A. Mehlich, "Mehlich 3 soil test extractant: a modification of Mehlich 2 extractant," Communications in Soil Science \& Plant Analysis, vol. 15, no. 12, pp. 1409-1416, 1984.

[21] J. M. Bremmer and D. R. Keeney, "Determination and isotopic ratio analysis of different forms of nitrogen in soils: I. Apparatus and procedure for distillation for and determination of ammonium," Soil Science Society of America Proceedings, vol. 29, pp. 504-507, 1965.

[22] K. W. Roy, W. F. Moore, and T. S. Abney, "Diagnosis of sudden death syndrome of soybean," Plant Diagnostics Quarterly, vol. 12, pp. 166-168, 1991.

[23] M. I. S. Ezenwa, "Some physico-chemical characteristics of soils of basement complex and adjoining basaltic rocks of Northern Ngeria," in Proceedings of the 15th Annual Conference of Soil Science Society of Nigeria, O. Babalola, Ed., pp. 205-214, 1987.

[24] I. E. Esu, "Fertility status and management of some upland basement complex soils in th Nigerian tropical savanna region," Nigerian Journal of Soil Science, vol. 7, pp. 155-184, 1987.

[25] S. Shoji, M. Nanzyo, and R. A. Dahlgren, "Chemical characteristics of volcanic ash soils," in Volcanic Ash Soils: Genesis, Properties and Utilization, vol. 153, pp. 166-167, 1993.

[26] E. Marcano-Martinez and M. B. McBride, "Calcium and sulfate retention by two oxisols of the Brazilian Cerrado," Soil Science Society of America Journal, vol. 53, no. 1, pp. 63-69, 1989.

[27] S. M. Ndala, M. C. Scholes, and M. V. Fey, "Soil properties and processes driving the leaching of nitrate in the forested catchments of the eastern escarpment of South Africa," Forest Ecology and Management, vol. 236, no. 2-3, pp. 142-152, 2006.

[28] C. V. Toner, D. L. Sparks, and T. H. Carski, "Anion exchange chemistry of Middle Atlantic soils: charge properties and nitrate retention kinetics," Soil Science Society of America Journal, vol. 53, no. 4, pp. 1061-1067, 1989. 

